\title{
SCANNING ELECTRON MICROSCOPY OF THE LUMINAL EPITHELIUM OF THE MOUSE UTERUS
}

\author{
ESTHER G. JONES AND J. D. HAMER* \\ Department of Anatomy, The Medical School, Birmingham B15 2TJ, and \\ *Department of Surgery, Queen Elizabeth Hospital, Birmingham B15 2 TH
}

(Received 20th May 1974)

\begin{abstract}
Summary. Four methods of manipulating mouse uterine tissue during fixation, preparatory to examination of the luminal epithelium by scanning electron microscopy (S.E.M.), are described and the results assessed. The appearance of the epithelium varies according to the technique used, the choice of method depending on the type of information required from the S.E.M. study. Surface topography is preserved in a condition most closely resembling that of fresh tissue by opening the uterus and fixing the tissue flat. Critical examination of cellular and subcellular surface detail, however, depends on adequate spreading of the epithelial layer during fixation by distension of the uterine lumen under positive pressure.

The method of tissue manipulation has a more profound effect on the appearance of the sample than any of the dehydration techniques which follow. For routine S.E.M. examinations at medium magnifications $(<\times 10,000)$, specimens which were air dried from alcohol, acetone or ether, or freeze dried, gave satisfactory results. Air drying from amyl acetate, and $\mathrm{CO}_{2}$ critical-point drying gave superior results at higher magnifications $(>\times 10,000)$ with better preservation of individual microvilli.
\end{abstract}

\section{INTRODUCTION}

The advent of the scanning electron microscope (S.E.M.) has given impetus to examination of topographical detail in biological material at high magnification and high resolution. The female reproductive system of a variety of mammals has now been extensively studied using this technique and details of surface ultrastructure are available for ovarian cells, blastocysts, and the epithelial lining of the Fallopian tube, uterus and cervix (see Jordan \& Williams, 1971; Motta, Cherney \& Didio, 1971; Psychoyos \& Mandon, 1971; Bergström, 1972; Dirksen \& Satir, 1972; Ferenczy, Richart, Agate, Purkerson \& Dempsey, 1972a, b; Hafez, 1972; Hafez \& Kanagawa, 1972; Johannison \& Nilsson, 1972; Kanagawa, Hafez, Pitchford, Baechler \& Barnhart, 1972; Nilsson, 1972; Patek, Nilsson \& Johannison, 1972a, b; Patek, Nilsson, Johannisson, Hellema \& Bout, 1973; Gould, 1973; Porter, Prescott \& Frye, 1973; Psychoyos, 1973; Williams, Jordan, Allen \& Murphy, 1973; Rumery \& Eddy, 1974). 
The surface ultrastructure of the luminal epithelium of the normal mouse uterus has not apparently been described. Earlier transmission electron microscope studies have established that the structure of the luminal epithelial cells varies according to the degree of ovarian hormone stimulation and, in particular, that a positive relationship exists between the number and size of microvilli and the amount of circulating oestrogen (Nilsson, 1958). These hormonedependent surface phenomena are ideally suitable for investigation by the S.E.M., which, by virtue of the wide range of magnification and depth of focus, gives an immediate visual image of comparatively large surface areas and of minute detail within specifically selected regions, without the tedium of serial reconstruction of numerous, effectively two-dimensional, transverse sections.

The present series of S.E.M. observations on the mouse uterus was undertaken for three reasons. First, to determine the appearance of the luminal surface of normal uterine tissue in females of known age and comparable physiological status. Second, to investigate the effects on the subsequent S.E.M. image of different methods of tissue manipulation during fixation, and, finally, to establish procedures of specimen preparation which yield reproducible results in order that future observations on tissue from experimental animals are amenable to consistent and meaningful interpretation.

\section{MATERIALS AND METHODS}

Nulliparous CBA female mice, 3 months of age, were killed during the morning of Day 1 (i.e. the day on which a vaginal plug was found) of the first pregnancy. In this condition, the uterine horns are dilated with fluid and easy to manipulate. Furthermore, since the appearance of the luminal epithelium differs according to the stage of the oestrous cycle (E. C. Jones \& S. J. Dipple, unpublished observation) an attempt was made to eliminate this source of variability by studying tissue from females in one well-defined physiological state.

After dissecting out the reproductive tract, the uterine horns were cut at the oviducal and cervical ends, trimmed of fat and mesentery and washed thoroughly (using Hanks' balanced salt solution) both internally and externally to remove blood and mucus (Barber \& Boyde, 1968). Each horn was divided transversely into two, and the resulting four pieces of tissue from a single individual were each subjected to one of four different methods of manipulation during fixation (Text-fig. 1). The fixative used throughout was a $5 \%$ solution of glutaraldehyde in $0.2 \mathrm{M}$-sodium cacodylate buffer, kept at $4^{\circ} \mathrm{C}$ and at $\mathrm{pH}$ $7 \cdot 4$.

\section{Method 1}

The luminal surface was exposed by cutting along the mesometrial side. The tissue was then spread out flat, arranged on a card without stretching, and fixed with the endometrium uppermost.

\section{Method 2}

The approximate length of the non-contracted horn before dissection was noted. After exposing the endometrial surface and spreading the tissue flat on 
card, an attempt was made to stretch the horn to the original length and to anchor it in place using a stainless-steel pin at each corner. The appearance of the luminal surface was assessed before fixation using a dissecting microscope at a magnification of $\times 50$.

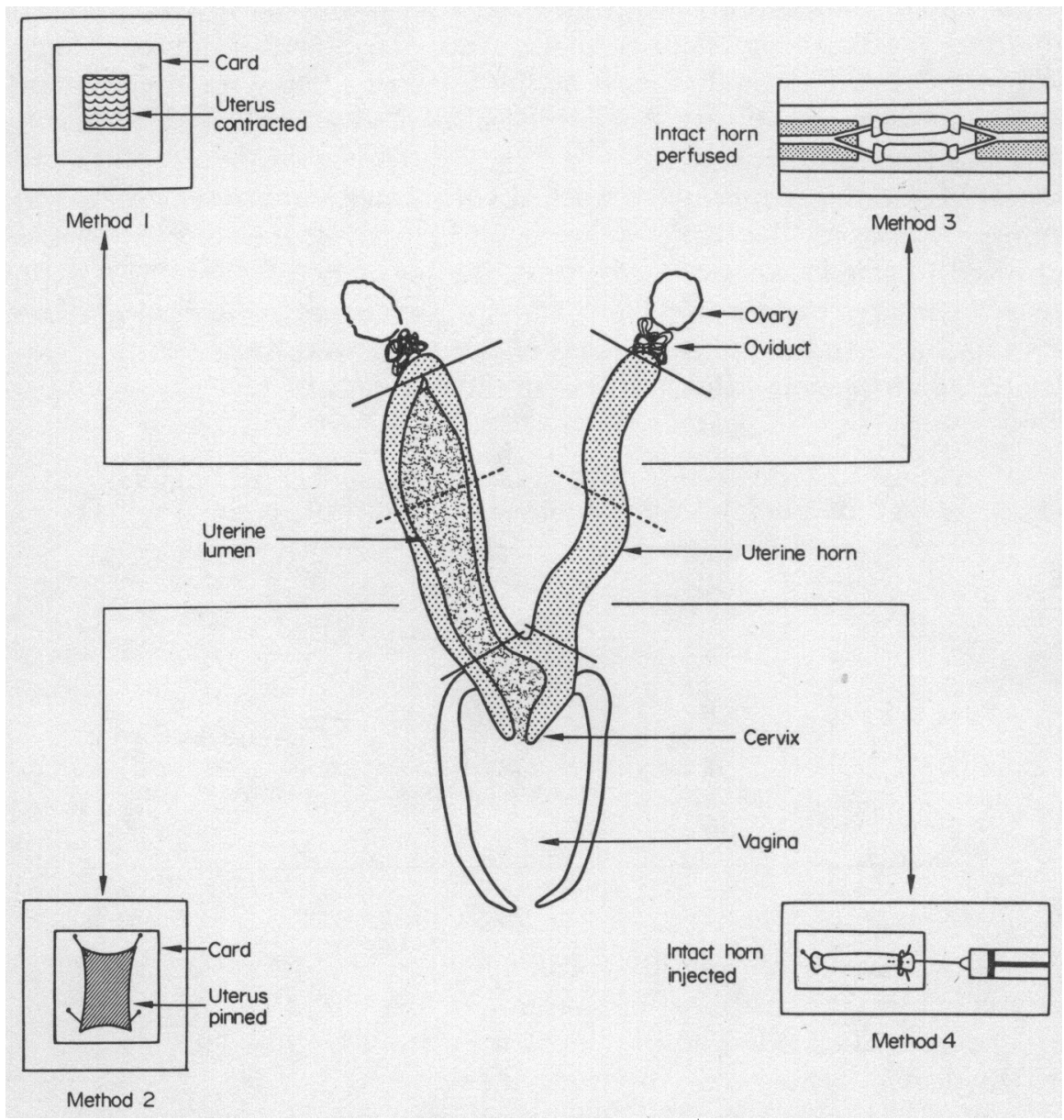

Text-FIG. 1. Diagram depicting the four methods used to prepare the uterus of a mouse at Day 1 of pregnancy for scanning electron microscopy.

\section{Method 3}

The intact horn was perfused intraluminally; details of the method have been described elsewhere (Hamer \& Fejfar, 1973). Fixation, washing and alcohol desiccation were accomplished by perfusion of reagents through the lumen at controlled pressure, with each specimen immersed in the appropriate medium.

\section{Method 4}

The oviducal end of the horn was firmly ligated and held in place on a cork board by a pin distal to the ligature. A loose ligature was placed round the 
cervical end, and fixative was introduced into the lumen using a syringe and hypodermic needle. The process of distension was followed under a dissecting microscope. The amount of fixative which could be injected into the lumen was determined by the physiological state of the tissue (unpublished observation) and prolonged pressure on the plunger resulted only in overflow of fixative. The second ligature was tightened on withdrawal of the hypodermic needle and the resulting 'sausage-shape' was placed into additional fixative solution for $1 \mathrm{hr}$. The ligated ends of the injected uteri were then cut off to allow free passage of reagents. A similar technique was used by Hamer (1972) for fixing segments of artery.

For all Methods, the uteri were washed with water. A variety of dehydration techniques was tried, the tissues being finally air dried, freeze dried or critical point dried (Table 1). Dissection of intact tubular uteri (Methods 3 and 4) took place in the final dehydration solvent, fine spring scissors being used to cut each horn in half longitudinally. Both parts of the horn were kept for observation, but only the antimesometrial half was studied in detail.

Table 1. Dehydration techniques and number of samples of uteri of CBA mice examined at Day 1 of gestation

\begin{tabular}{cc|c|l|l}
\hline $\begin{array}{c}\text { No. of } \\
\text { females }\end{array}$ & $\begin{array}{c}\text { No. of } \\
\text { samples }\end{array}$ & \multicolumn{1}{|c|}{$\begin{array}{c}\text { Dehydration } \\
\text { solvent }\end{array}$} & \multicolumn{1}{|c}{$\begin{array}{c}\text { Drying } \\
\text { technique }\end{array}$} \\
\cline { 2 - 4 } & 8 & 32 & Alcohol & Air \\
& 2 & 8 & Acetone & Air \\
& 2 & 8 & Alcohol-ether & Air \\
& 3 & 12 & Alcohol & Freeze dry \\
& 1 & 4 & Alcohol-amyl acetate & Air \\
Total & 1 & 4 & Alcohol-amyl acetate & Critical point \\
& 17 & 68 & & \\
\hline
\end{tabular}

Fifty-two pieces of uterine horn from thirteen females were pinned out on polystyrene blocks covered with aluminium foil, air dried and stored in a desiccator over silica gel. The specimens from three females (twelve segments) were dehydrated by freeze drying using the regimen described by Johannisson \& Nilsson (1972) for S.E.M. studies on the human endometrium. Ethanol dehydration was followed by quenching in isopentane cooled to $-150^{\circ} \mathrm{C}$ in liquid nitrogen. The specimens were transferred to the stage of a Pearce Edwards freeze dryer and dried overnight at $-40^{\circ}$ to $-60^{\circ} \mathrm{C}$ under vacuum $(0.01 \mathrm{mmHg})$. The remaining four specimens were transferred from ethanol into amyl acetate and finally dried from $\mathrm{CO}_{2}$ using the critical-point method.

The dried specimens, mounted on specimen stubs with Durofix, were coated with a layer, approximately $200 \AA$ thick, of a $60 / 40 \%$ gold-palladium alloy. The coating was effected by vacuum deposition in conventional equipment (Edwards High Vacuum Ltd; Model 12 E3) operating at $1 \times 10^{-4} \mathrm{mmHg}$. Even deposition of the metal was ensured by rotating the stubs during the coating process. Examinations were made using a Cambridge (Stereoscan) Mark II scanning electron microscope, with a beam specimen angle of $45^{\circ}$, 
accelerating voltage of $20 \mathrm{kV}$, and at magnifications ranging from approximately $\times 100$ to $\times 20,000$. The specimens were always viewed with the longitudinal axis of the uterus running vertically.

\section{RESULTS}

On Day 1 of pregnancy, the surface of the freshly exposed luminal epithelium, examined by a dissecting microscope using incident light, shows regular convolutions, with prominent transversely running ridges of tissue occurring at intervals along the horn. Cutting the horn resulted in contraction to an estimated one-third to one-quarter of its original length and further rapid contraction along the longitudinal axis took place during fixation using Method 1, although the tissue usually remained flat. Gentle stretching and pinning (Method 2) prevented longitudinal contraction. Some lateral shrinkage occurred but this did not distort the main topographical features previously noted in the fresh condition. Shrinkage was minimal after either continuous intraluminal perfusion (Method 3) or intraluminal injection of fixative (Method 4), and the transverse ridges remained clearly visible through the intact uterine wall.

The general appearance of the luminal surface as viewed by the S.E.M. at low magnification varied according to the method of fixation. When the horn was allowed to contract without restraint (Method 1), the convolutions, normally seen in unfixed uterine tissue using a dissecting microscope, were extremely exaggerated (P1. 1, Fig. 1). This degree of distortion obliterated the major topographical features, and structural detail between the transverse ridges was obscured. The S.E.M. image of tissue which had been fixed flat but under tension (Method 2) closely resembled that of unfixed tissue seen with a dissecting microscope, and the major features were retained and recognizable. The structure of the papilliform projections, also seen in the wet tissue, is apparently characteristic of the CBA strain (Pl. 1, Fig. 2). Continuous perfusion of the intact horn under slight positive pressure (Method 3) resulted in further spreading and flattening of the tissue between the transverse ridges and gave a clearer indication of the spatial arrangement of the papillae (Pl. 1, Fig. 3), but the characteristic natural surface topography was grossly distorted. Similar results were obtained using Method 4 and the papillae were again conspicuous in the completely flattened surface (Pl. 1, Fig. 4).

The shape of the papillae referred to above and the appearance of the luminal epithelium were also dependent on the method of fixation (Pl. 2, Figs 5 to 8 ). The endometrial convolutions in the non-dilated specimens showed a 'pin-cushion' effect, the 'studs' probably representing dead or dying epithelial cells which had been extruded from the surface (Pl. 2, Figs 5 and 6). With increasing intraluminal pressure the convolutions were progressively flattened, resulting finally in a completely smooth sheet of cells (PI. 2, Figs 7 and 8).

The method of specimen preparation influenced the shape of individual cells which ranged from rounded to completely flattened, and was accompanied by an apparent change, not only in the density of microvilli, but also in cell size (Pl. 3, Figs 9 to 12). Plate 3, Fig. 9 demonstrates that the microvilli were not uniformly distributed and that, whereas the majority of cells possessed a 
dense covering, some were partly denuded, and others were completely naked. Compression of cells, with attendant bunching of the microvilli, was eliminated after fixing the uterus in a distended state. The outlines of individual cells were distinguishable after using Method 3 (Pl. 3, Fig. 11), but Method 4 gave the best result in terms of number and distribution of microvilli, and the boundaries between cells were also more readily seen (Pl. 3, Fig. 12).

The use of different dehydration and final drying procedures appeared to have very little effect on the subsequent S.E.M. image at low to medium magnifications. Air drying from ethanol, acetone, or ether gave equally good results. With amyl acetate as the final solvent before air drying, the results were marginally improved but this effect only became apparent at the higher magnifications of $\times 10,000$ and $\times 20,000$ (Pl. 4, Figs 15 and 16). No significant differences in appearance could be detected between tissues which were either dried in air from amyl acetate or by the critical point method, and the superiority of the latter method again became apparent only at magnifications above $\times 10,000$ (Pl. 4, Figs 13 and 14). The appearance of the samples was not improved by freeze drying after dehydration in alcohol.

\section{DISCUSSION}

One inherent difficulty facing the scanning electron microscopist concerns the possible distortion of soft biological material by fixation and dehydration procedures. In order to assess the degree of distortion due to tissue preparation, careful note was taken, when possible in the present study, of the appearance of the surface of fresh tissue using a dissecting microscope. This compared favourably with the appearance of fixed and dehydrated tissue observed at low magnification by the S.E.M.

When the tissue was preserved without artificial distension of the uterine lumen, the most conspicuous features of the luminal surface were the transverse ridges occurring at intervals throughout the length of the horn, the convolutions of the epithelium, an abundance of papillae opening onto the antimesometrial surface and the microvilli which cover most cell surfaces. Although the papillary structures have not been positively identified, it is likely that they represent the exits from uterine glands, since strands of material have been observed emerging from these openings in incompletely washed specimens. Furthermore, the number of openings varies in phase with the oestrous cycle during which they appear most abundantly at pro-oestrus and oestrus (E. C. Jones and S. J. Dipple, unpublished observation). The presence of microvilli confirms previous observations made by transmission and scanning electron microscopy of the rat uterus during artificially induced delay of implantation and at later stages of normal pregnancy (Nilsson, 1970, 1972; Psychoyos, 1973), but the microvilli in the present study appear to be moniliform rather than digitiform. Their pattern of distribution probably reflects the state of cellular metabolism and may relate to the normal cycle of cell death which is known to occur in this epithelium (Walker, 1960; Bertalanffy \& Lau, 1963).

The method of tissue manipulation during fixation has a significant effect 

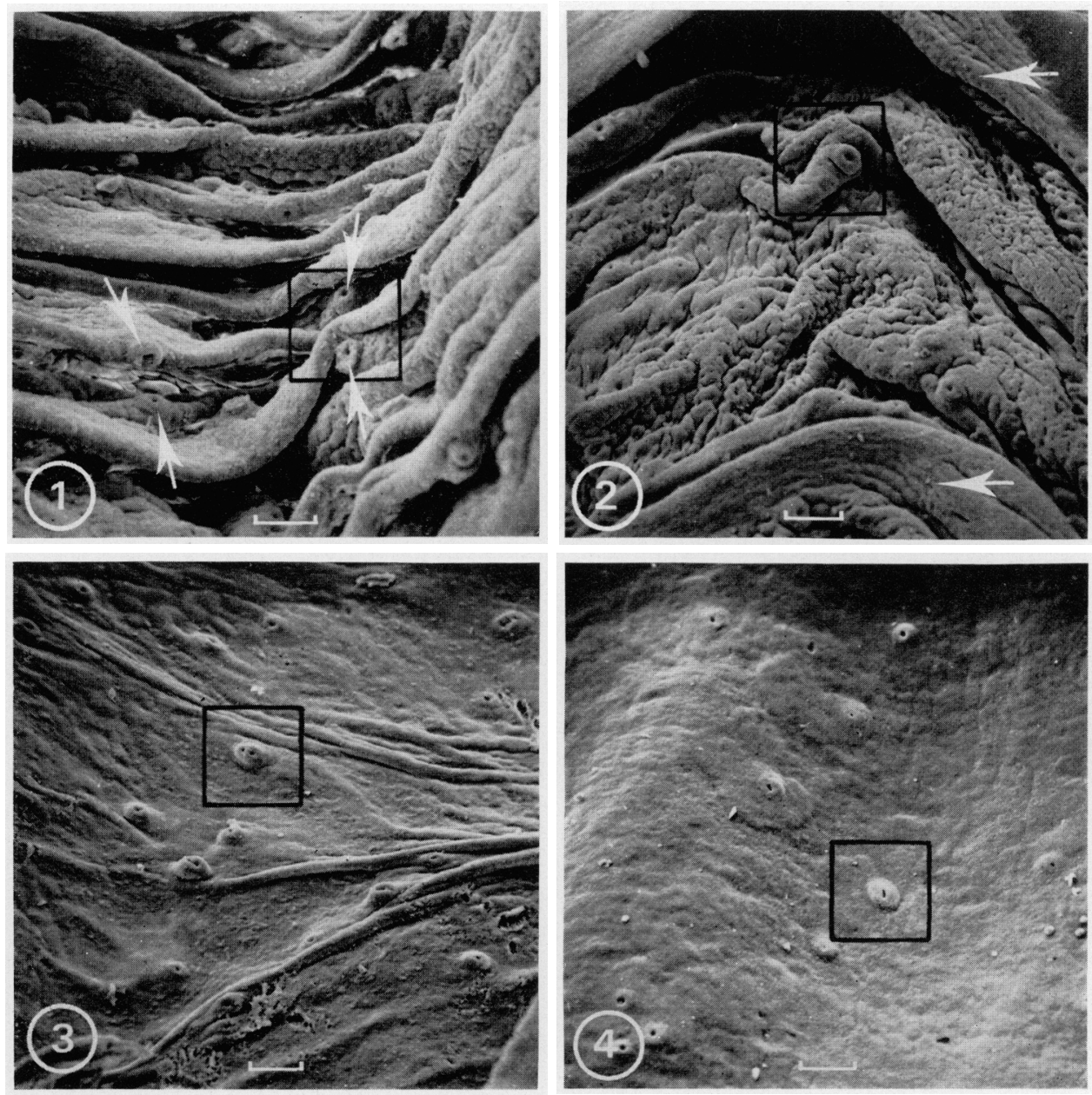

T'opographical features of the antimesometrial surface of mouse uterine epithelium on Day l of pregnancy. Bar line represents $100 \mu \mathrm{m}$.

Fig. 1. Fixation by Method 1. The major transwerse ridges have contracted and the intervening tissue is almost totally obscured. Numerous papillac with openings (arrows) can be seen.

lis, 2. Fixation by Method 2. Two of the major transerse ridges are seen at the top and bottom of the figure (arrows). The intervening tissue is exposed and shows clearly the highly convoluted nature of the surface. This illustration closely resembles the appearance of the epithelium in the fresh condition.

I'It. 3. Fixation by Method 3. Distension of the utcrus results in spreading and flattening of the tissue and gives an indication of the distribution and number of uterine papillat. pre-fixation tissue damage is seen in the lower right guadrant.

Fic. 4. Fixation by Method 4. Maximum flatening and spreading achieved. with distortion of some uterine "gland' openings. 

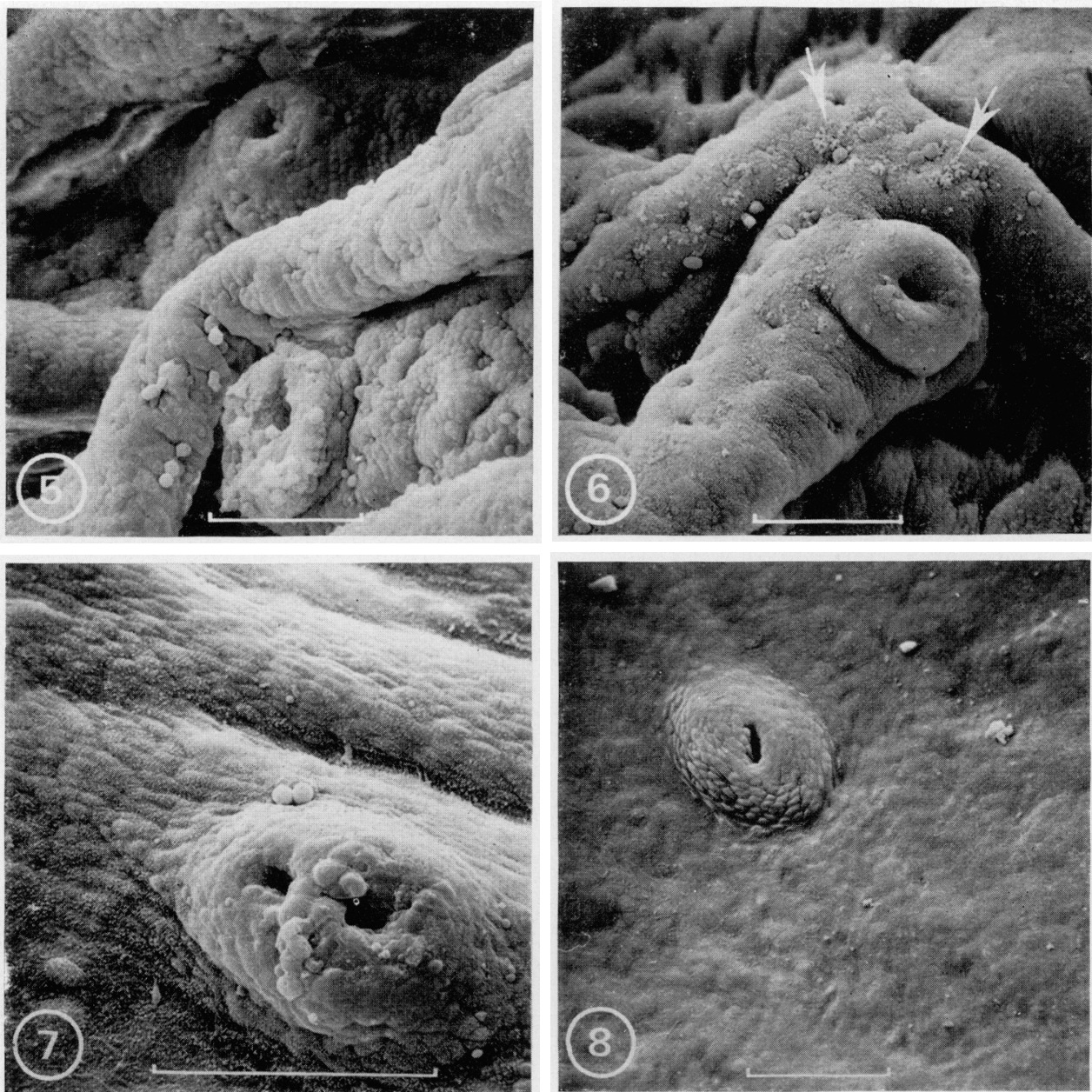

Detail of pabillac (within squares on Plate 1) on the antimesometrial surface mouse uterus on bay l of pregnancy. Bar line represents $50 \mu \mathrm{m}$.

Fig. 5. Fixation by Method I. Contracted surface epithelium and two 'gland' openings. The rim of the lower structure is covered by non-cellular deposit. thought to be secretory material. Individual cells can be seen.

Fig. 6. Fixation by Method 2. Endometrial convolutions showing 'pin-cushion' effect and one 'gland' opening. (iell boundaries are visible and the microvillous surface clearly indicated. The lighter lireadlike structures (arrows) on the transverse convolution are believed to be artefacts due to deposition of extraneous material.

Fic. T. Fixation by Method 3. The convolutions have becn eliminated but gentle undulations remain. Cell boundaries and microvilli are clear. but because of the slightly convex cell surface, the cell outlines are not well displayed.

Fic. 8. Fixation by Method 4. Completely flattened and smooth cpithelium. surrounding one 'gland' opening. 

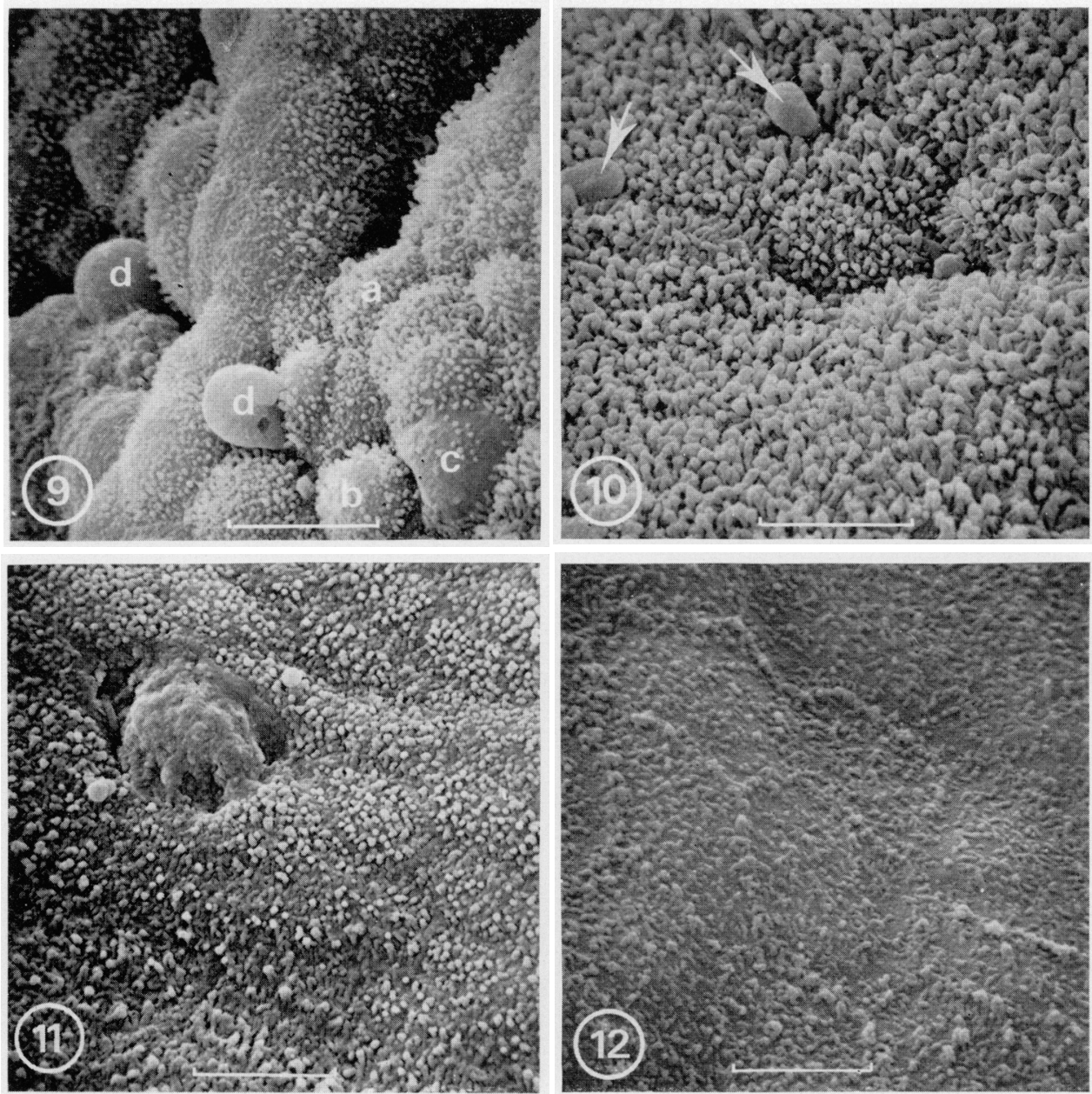

Details of cellutar and sub-cellular structure on the antimesometrial surface of the mouse uterus on Day 1 of pregnancy. Bar line represents i $\mu \mathrm{m}$.

Fic. 9. Fixation by Method 1. The cells are squashed as a result of contraction and have an exaggerated convex surface. Four cell types can be distinguished: a, completely covered with dense mic rovilli; b, partly covered with small squat microvilli; $c$, almost completely denuded; d. completely denuded. The denuded cells appear to be oozing out from the epithelial layer.

lig. 10. Fixation by Method 2. Cellular limits are difficult to distinguish and the microvilli appear to be extremely densely packed. Two clongated and denuded structures lie superficially. Compare with Fig. 9.

Frc. 11. Fixation by Method 3. Cell outlines are distinguishable. The accumulation of the non-cellular substance in the upper left quadrant probably represents secretory material.

Fig. 12. Fixation by Method 4. Maximum flattening has resulted in an apparent increase: in cell size with accompanying apparent reduction in the number of microvilli. Cell outlines are casily seen. 

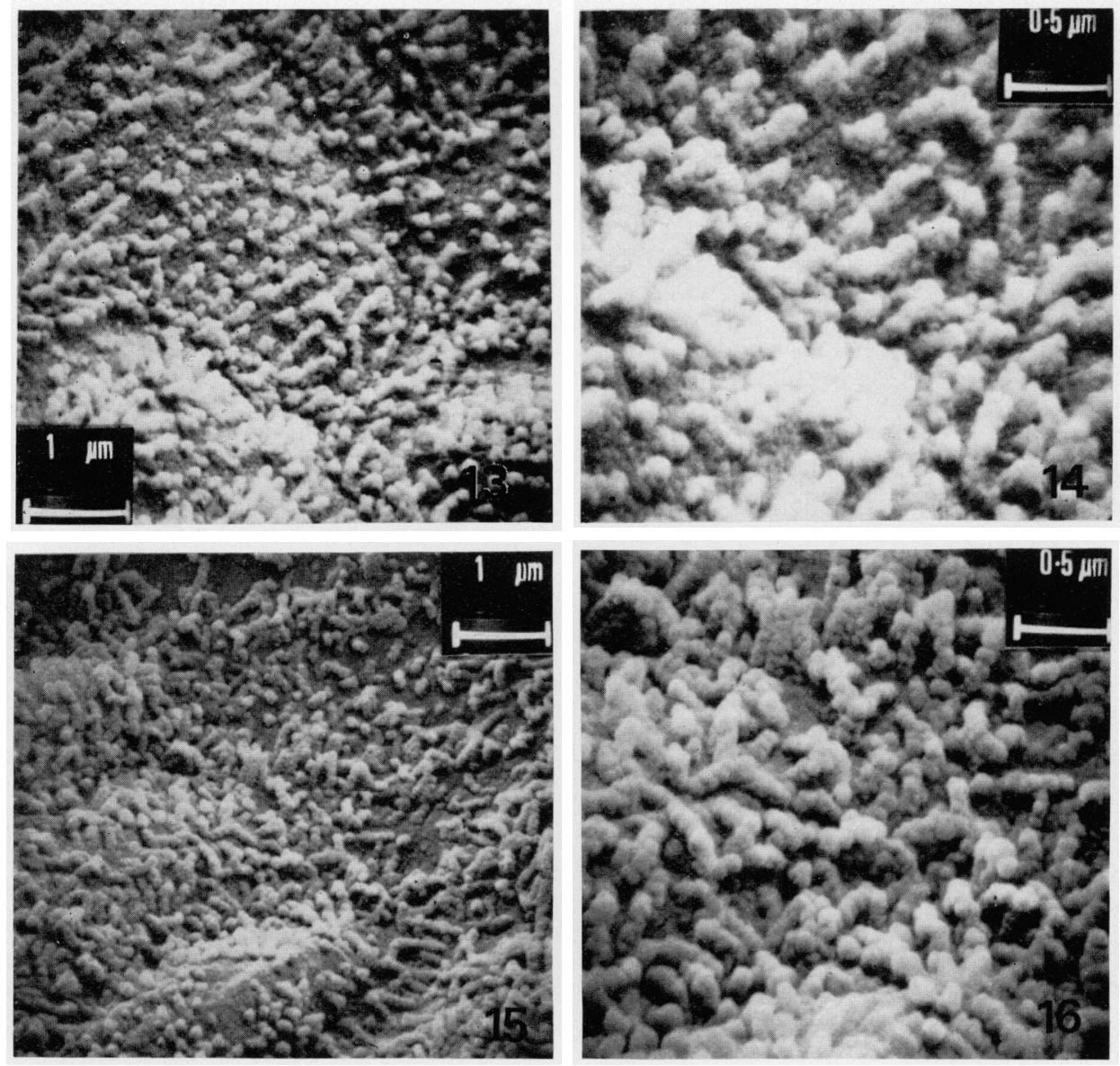

Comparison between critical point and air dried mouse uterus material showing details of the cell surface and moniliform microvilli.

Fic. 13. Tissue dried using the critical point method.

Fici. 14. Tissue dried using the critical point method.

Fic. 15. Tissue dried in air from amyl acetate.

Fis. 16. Tissue dried in air from amyl acetate. 
on the appearance of the S.E.M. image, a conclusion reached previously for the reproductive tract of the rabbit (Kanagawa, Hafez, Baechler, Pitchford \& Barnhart, 1972). The choice of a particular technique depends on the type of information required from the S.E.M. study and on the type of tissue under examination. The technique of fixation by intravascular perfusion, generally recognized by transmission electron microscopists to give the most satisfactory results, was considered to be unsuitable in this instance for the following reason. A clean surface is desirable for S.E.M. studies, since deposition of extracellular material totally obscures underlying appearances. On the first day of pregnancy the uterine horns contain not only the fluid secreted at oestrus, but also ejaculate from the male. These fluids, together with suspended spermatozoa, must be removed by thorough flushing of the isolated horns before fixation. In the dioestrous phase of the oestrous cycle, and during later stages of the preimplantation phase of pregnancy, the volume of uterine fluid decreases, and the problems associated with surface deposits diminish accordingly (E. C. Jones and S. J. Dipple, unpublished observation).

For preservation of the surface architecture in a condition most closely resembling that seen in fresh tissue, distension of the uterus during fixation (Methods 3 and 4) is not recommended. Method 2 preserved the tissue surface in this state, but is not satisfactory for detailed examination of cellular and subcellular surface structure, which depends on flattening and spreading of the epithelium under positive pressure. The two methods which satisfied these latter requirements were intraluminal perfusion and injection. The most important single advantage conferred by use of the perfusion method is that experimental and control tissue can be prepared in an identical chemical and physical environment. Any degree of distension of tubular specimens can be achieved by alteration of the pressure gradient across the wall of the uterine horn, and the method can equally well be applied to other tissue with a tubular organization, e.g. artery and gut. A disadvantage of the method applied to the mouse uterus is that the natural elasticity of the muscle, even between individuals of the same age and in the same physiological condition, varies considerably. Constant pressures of reagents within the uterus may not, therefore, result in equivalent degrees of distension in specimens from different females. Furthermore, the delay in attaching the uterine horns to the apparatus resulted in a degree of pre-fixation tissue damage. The advantages of the intraluminal injection method are that the tissue can be fixed with minimum delay and the degree of distension achieved is controlled by the natural elasticity of the uterine walls.

Standardized procedures for dehydration of soft biological material have not yet been established (Kanagawa, Hafez, Baechler, Pitchford \& Barnhart, 1972). Since one of the major objects of this investigation was to determine the effects of different methods of manipulating the uterus during fixation, most of the specimens were dehydrated using the simplest possible technique, i.e. alcohol desiccation followed by air drying. The mouse uterus is a relatively robust tissue, and the luminal epithelium, with the underlying support of both stroma and myometrium, appeared to tolerate the rigours of final air drying without obvious distortion. The absence of clefts on cell surfaces and the preservation of the microvilli is taken as evidence that the tissue has not been 
unduly stressed by surface tension forces. There was no evidence to show that the results after freeze drying were superior to those obtained after air drying. A similar conclusion has been drawn from S.E.M. investigations on the vascular system (Hamer, 1972) and on normal, metaplastic and abnormal epithelia of the human cervix (Williams et al., 1973). Delicate and unsupported structures such as cilia (e.g. ciliated epithelium of the Fallopian tube), isolated cells and hollow spheres of cells, e.g. blastocysts (Bergström, 1972) undoubtedly benefit from a method of dehydration which reduces (freeze drying) or eliminates (critical point drying) the effects of surface tension forces. Our experiments using the critical point method of drying mouse uterine tissue indicate that this technique does give superior results more consistently, particularly with regard to preservation of surface detail on individual microvilli at high magnification.

The results of this investigation show that the method of fixation has a more profound effect on the subsequent appearance of the tissue than any of the dehydration routines which follow. Consistency within four fixation procedures has been achieved and although distension of the uterus obviously destroys the natural surface characteristics of the uterine mucosa, fixation by Method 4 has proved of value in spreading the epithelial cell layer. As long as the uterine lumen of the pregnant mouse remains open, the process of distension by intraluminal injection of fixative can be useful in studies of a comparative nature. Flattening of the epithelium displays cell boundaries more effectively and numerical assessment of the pictorial information becomes possible. Preliminary counts after using this method have shown, for example, that the number of cells per unit area, and the proportion of cells with and without microvilli, vary throughout the oestrous cycle (E. C. Jones and S. J. Dipple, unpublished observation). During later stages of the preimplantation period, distension of the uterus becomes increasingly difficult and finally impossible. The close apposition of the epithelial surfaces during luminal closure is a recognized part of the implantation process (Nilsson, 1966; Potts, 1969) and to preserve this relationship the fixation method of choice is intravascular perfusion. The natural configuration of the epithelial layer can be subsequently exposed by careful dissection of the fixed specimen (Nilsson, 1972) but a mathematical assessment of this type of preparation is virtually impossible.

Material preparation methods which yield reproducible results have been established for uterine tissue from normal mice in a known physiological state. Preliminary work using these methods has shown that there are significant differences in the surface architecture of young and old tissues (Jones, 1974). These studies are now being extended to include the effects of increasing age on surface topography of the luminal epithelium during the oestrous cycle, and throughout the preimplantation stages of pregnancy, and will be the subjects of further reports.

\section{ACKNOWLEDGMENTS}

We thank Mrs S. J. Dipple and Mrs C. Crozier for their technical assistance, and Mrs P. Fisher (Centre for Materials Science, University of Birmingham) for scanning electron microscopy service. We are indebted to Mrs Mary Warren 
(Cambridge Scientific Instruments Ltd) for preparing the photomicrographs shown in Plate 4.

Grateful acknowledgment is made to the Medical Research Council, the United States Atomic Energy Commission and the United Birmingham Hospitals Endowment Fund for financial support.

\section{REFERENCES}

BARber, V. C. \& Boyde, A. (1968) Scanning electron microscopic studies of cilia. Z. Zellforsch. mikrosk. Anat. 84, 269-284.

Bergström, S. (1972) Delay of blastocyst implantation in the mouse by ovariectomy or lactation. A scanning electron microscope study. Fert. Steril. 23, 548-561.

Bertalanffy, F. D. \& LaU, C. (1963) Mitotic rates, renewal times and cytodynamics of the female genital tract epithelia in the rat. Acta anat. 54, 39-81.

Dirksen, E. R. \& Satir, P. (1972) Ciliary activity in the mouse oviduct as studied by transmission and scanning electron microscopy. Tissue $\mathcal{E}^{\circ}$ Cell, 4, 389-404.

Ferenczy, A., Richart, R. M., Agate, F. J., Purkerson, M. L. \& Dempsey, E. W. (1972a) Scanning electron microscopy of the human Fallopian tube. Science, N.Y. 175, 783-784.

Ferenczy, A., Richart, R. M., Agate, F. J., Purkerson, M. L. \& Dempsey, E. W. (1972b) Scanning electron microscopy of the human endometrial surface epithelium. Fert. Steril. 23, 515-521.

Gould, K. G. (1973) Preparation of mammalian gametes and reproductive tract tissues for scanning electron microscopy. Fert. Steril. 24, 448-456.

Hafez, E. S. E. (1972) Scanning electron microscopy of rabbit and monkey female reproductive tract epithelium. F. Reprod. Fert. 30, 293-296.

Hafez, E. S. E. \& Kanagawa, H. (1972) Giliated epithelium in the uterine cervix of the macaque and rabbit. F. Reprod. Fert. 28, 91-94.

HAMER, J. D. (1972) Arterial embolism: an experimental study, pp. 55 and 62. Ch.M. thesis, University of Birmingham.

HAMER, J. D. \& FrJFar, J. (1973) Studies on arterial thrombosis: techniques of tissue preparation for scanning electron microscopy. Proc. R. Soc. Med. 66, 1099-1102.

Johannisson, E. \& NiLsson, L. (1972) Scanning electron microscopic study of the human endometrium. Fert. Steril. 23, 613-625.

JonEs, E. C. (1974) The endometrium and effects of aging. In S.E.M. Atlas of Mammalian Reproduction. Ed. E.S.E. Hafez. Igaku Shoin, Tokyo.

Jordan, J. A. \& Williams, A. E. (1971) Scanning electron microscopy in the study of cervical neoplasia. 7. Obstet. Gynaec. Br. Commonw. 78, 940-946.

Kanagawa, H., Hafez, E. S. E., Baechler, C. A., Pitchford, W. C. \& Barnhart, M. I. (1972) Improved methodology for scanning electron microscopy of the female reproductive tract. Int. F. Fert. 17, 75-80.

Kanagawa, H., Hafez, E. S. E., Pitchrord, W. C., Baechler, C. A. \& Barnhart, M. I. (1972) Surface patterns in the reproductive tracts of the rabbit observed by scanning electron microscopy. Anat. Rec. 174, 205-226.

Motta, P., Cherney, D. D. \& Didro, L. J. A. (1971) Scanning and transmission electron microscopy of the ovarian surface in mammals with special reference to ovulation. 7. submicr. Cytol. 3,85-100.

NiLsson, O. (1958) Ultrastructure of mouse uterine surface epithelium under different estrogenic influences. 2. Early effect of estrogen administered to spayed animals. F. Ultrastruct. Res. 2, 73-95.

NiLsson, O. (1966) Estrogen-induced increase of adhesiveness in uterine epithelium of mouse and rat. Expl Cell Res. 43, 239-241.

NILsson, O. (1970) Some ultrastructural aspects of ovo-implantation. In Ovo-Implantation, Human Gonadotropins and Prolactin, pp. 52-72. Eds. P. O. Hubinont, F. Leroy, C. Robyn and P. Leleux. Karger, Basel.

NiLsson, O. (1972) Ultrastructure of the process of secretion in the rat uterine epithelium at preimplantation. F. Ultrastruct. Res. 40, 572-580.

Patex, E., Nilsson, L. \& Johannisson, E. (1972a) Scanning electron microscopic study of the human Fallopian tube. Report I. The proliferative and secretory stages. Fert. Steril. 23, 459-465.

Patek, E., Nilsson, L. \& Johannisson, E. (1972b) Scanning electron microscopic study of the human Fallopian tube. Report II. Fetal life, reproductive life and postmenopause. Fert. Steril. 23, 719-733.

Patex, E., Nilsson, L., Johannisson, E., Hellema, M. \& Bout, J. (1973) Scanning electron microscopic study of the human Fallopian tube. Report III. The effect of mid-pregnancy and of various steroids. Fert. Steril. 24, 31-43. 
Porter, K., Prescotr, D. \& Frye, J. (1973) Changes in surface morphology of Chinese hamster ovary cells during the cell cycle. F. Cell Biol. 57, 815-836.

Potrs, M. (1969) The ultrastructure of egg implantation. Adv. Reprod. Physiol. 4, 241-267.

Psychoyos, A. (1973) Endocrine control of egg implantation. In Handbook of Physiology, Section 7, Vol. 2, Pt. 2, pp. 187-215. Ed. R. O. Greep. American Physiological Society, Washington.

Psychoyos, A. \& Mandon, P. (1971) Scanning electron microscopy of the surface of the rat uterine epithelium during delayed implantation. F. Reprod. Fert. 26, 137-138.

Rumery, R. E. \& Eddy, E. M. (1974) Scanning electron microscopy of the fimbriae and ampulla of rabbit oviducts. Anat. Rec. 178, 83-106.

Walker, B. E. (1960) Renewal of cell populations in the female mouse. Am. F. Anat. 107, 95-106.

Williams, A. E., Jordan, J. A., Allen, J. M. \& Murphy, J. F. (1973) The surface ultrastructure of normal and metaplastic cervical epithelia and of carcinoma in situ. Cancer Res. 33, 64-73. 